\title{
LA LIBERTAD RELIGIOSA Y DE CULTOS EN COLOMBIA DESDE LA LEY 133 DE 1994, DESARROLLO CONSTITUCIONAL Y JURISPRUDENCIAL PARA LA PROTECCIÓN DE LAS CREENCIAS DESDE LA PERSPECTIVA DE LOS DERECHOS HUMANOS
}

\section{[Religious freedom and freedom to worship in Colombia from the Law 133 of 1994, constitutional development and case law from the protections of beliefs from the perspective of human rights]}

\author{
JUAN DAVID JURADO OCAMPO ${ }^{1}$ \\ CONSTANZA FRAUME RESTREPO².
}

\begin{abstract}
Resumen
El derecho a la libertad religiosa y de conciencia emerge con fuerza en las últimas décadas en los ordenamientos constitucionales y legales de las sociedades democráticas como la colombiana.

Actualmente toma gran vigor el tema de los fundamentalismos religiosos en el mundo y ascenso de muchos grupos religiosos en la actividad política, sobre todo en América Latina, sin dejar de reconocer que se constituyen en actores sociales y muy relevantes y cuestionados desde numerosos frentes.

La libertad religiosa y de cultos en Colombia; ha tenido un desarrollo histórico, constitucional y legal; y su evolución jurisprudencial a partir de sentencias de la corte Constitucional entre $1991-2015$. Teniendo en cuenta la influencia e implicaciones del derecho interamericano e internacional de los derechos humanos.

El objeto de abordar la evolución constitucional del derecho de la libertad religiosa en Colombia, permite realizar análisis histórico crítico de la evolución de dicho derecho y sus implicaciones en la sociedad.
\end{abstract}

Palabras clave

\footnotetext{
${ }^{1}$ Abogado egresado de la Universidad de Manizales, especialista en Investigación Criminal de la Dirección Nacional de Escuelas de la Policía Nacional de Colombia; Magíster en Derecho de la Universidad de Manizales, cursando el Doctorado en Literatura de la Universidad Tecnológica de Pereira. Docente de la Universidad de Manizales e investigador del grupo politica, criminal, víctima y delito de la misma institución. Participó en la creación de la política pública de libertad religiosa y de cultos en la ciudad de Manizales, Colombia.

${ }^{2}$ Abogada egresada de la Universidad de Manizales, especialista en Sistema Procesal Penal de la Universidad Manizales, Máster en Grafoanálisis europeo con Especialidad en: Grafística, Grafología Forense, Grafopatología (Universidad Autónoma de Barcelona - España). Participó en la creación de la politica pública de libertad religiosa y de cultos en la ciudad de Manizales, Colombia.
} 
Juan David Jurado Ocampo \& Constanza Fraume Restrepo, La libertad religiosa y de cultos en Colombia desde

la ley 133 de 1994, desarrollo constitucional y jurisprudencial para la protección de las creencias desde la perspectiva de los derechos humanos.

Libertad religiosa, libertad de cultos, derechos humanos, jurisprudencia, constitucionalización

\begin{abstract}
Summary
The religious and conscience rights emerge with force in the last decades with the constitutional and legal ordinances of the democratic societies, such as the Colombian one.

At the present time, the topic of religious fundamentalism is playing a big role in the world. Many religious groups are ascending and getting involved in political activities, especially in Latin America; without ceasing to recognize that they become relevant social actors. These groups, however, are questioned from numerous sides.

The religious and worship freedom in Colombia, has had a historic, constitutional and legal development; as well as the jurisprudential evolution of the constitutional court rulings between 19912015. The influences and implications from the International and Inter-American human rights, have to be taken into account and consideration.

The main reason for addressing the constitutional right for religious freedom in Colombia, allows for a crucial historic analysis of said right and the implications it has in society.
\end{abstract}

Keyword:

Religion freedom, freedom of worship, human rights, jurisprudence and constitutionalization

DOI: $10.7764 / R L D R .10 .128$ 


\section{LA LIBERTAD RELIGIOSA Y DE CULTOS EN EL DERECHO INTERNACIONAL}

A partir de la Constitución de 1991, el derecho a la libertad religiosa en Colombia se encuadra en un esquema de derechos fundamentales; que de acuerdo con los instrumentos, convenciones y tratados internacionales sobre derechos humanos se encuentran consolidados en dos sistemas generales de protección, uno de carácter universal y otro de carácter regional entre los que se destacan desde luego, la Declaración Universal de los Derechos Humanos (DUDH) de 1945; el Pacto Internacional de Derechos Civiles y Políticos (PICDP) de 1976; la Convención Americana sobre los Derechos Humanos (CADH) de 1969; la Convención Europea de Derechos Humanos (CEDH) de 1953 (la cual no es vinculante en nuestro país); los tratados de derecho internacional humanitario de 1949 en adelante y otros acuerdos y protocolos facultativos y dirigidos a promover el respeto y la protección irrenunciable de todos los derechos inherentes a las personas, en tanto la condición de seres humanos.

Tratados que han sido ratificados por Colombia (con excepción de la CEDH), e integrados por mandato constitucional al ordenamiento jurídico interno, y consolidados junto a la teoría sobre el bloque de constitucionalidad, en concordancia con el artículo 93 de la Constitución el cual señala: "Los tratados y convenios internacionales ratificados por el Congreso, que reconocen los derechos humanos y que prohíben su limitación en los estados de excepción, prevalecen en el orden interno. Los derechos y deberes consagrados en la Carta, se interpretarán de conformidad con los tratados internacionales sobre los derechos humanos ratificados por Colombia." 3

\footnotetext{
${ }^{3}$ Artículo 93 de la Constitución Política de Colombia del año 1991.
} 
Juan David Jurado Ocampo \& Constanza Fraume Restrepo, La libertad religiosa y de cultos en Colombia desde la ley 133 de 1994, desarrollo constitucional y jurisprudencial para la protección de las creencias desde la perspectiva de los derechos humanos.

Desde esta nueva perspectiva de derechos fundamentales, se reconoce, naturalmente, los derechos humanos de mayor trascendencia política y social, en el marco del Estado Social de derecho, los cuales armonizan como un cúmulo de principios medulares, de arraigo constitucional, como son: la dignidad humana, la solidaridad, la igualdad y la legalidad, entre otros. Todo esto dentro de una verdadera estructura compleja, que el Estado vela por mantener a través de sus órganos, corporaciones y entidades mediante el desarrollo de políticas, programas planes de desarrollo dirigidos a maximizar su reconocimiento y mayor grado de protección.

Dentro de este orden de ideas, se desarrollan los derechos fundamentales de primera generación, como el derecho a la vida, al trabajo, a la educación a la privacidad, a la libre locomoción, el derecho de petición, la libertad de conciencia, la libertad de religión y culto entre otros.

En consecuencia, la mayor parte de estos derechos han ido evolucionando de manera paulatina, su reconocimiento e interpretación se ha hecho cada vez más extensiva, y sus mayores grados de protección se han proyectado sobre la base de principios del derecho internacional como el pro homine, cuyo propósito es aplicar la interpretación más favorable y extensiva del ser humano, en especial cuando se trata del reconocimiento de los derechos humanos y al mismo tiempo, sugiere el grado más restrictivo de interpretación frente a las medidas y mecanismos que pretenden establecer límites para su reconocimiento y el principio pacta sunt servanda; con su significado que los tratados son para cumplirse, el principio de proporcionalidad; que propende por el equilibrio en sus efectos para el reconocimiento de los derechos; entre otros.; todo esto dentro de una labor compleja; que de forma valiente viene adelantando la Corte Constitucional, máxima guardiana de la integridad y supremacía de la Constitución. 
Juan David Jurado Ocampo \& Constanza Fraume Restrepo, La libertad religiosa y de cultos en Colombia desde la ley 133 de 1994, desarrollo constitucional y jurisprudencial para la protección de las creencias desde la perspectiva de los derechos humanos.

Ahora bien, uno de los derechos fundamentales de mayor avance y extensión internacional, es desde luego el derecho a "profesar libremente una religión y difundirla" estableciendo en el artículo 19 de la Constitución Política, que es expresión del artículo 18 de la DUDH (Declaración Universal de Derechos Humanos 1945), que al respecto señala:

"Toda persona tiene derecho a la libertad de pensamiento, de conciencia y de religión, este derecho incluye la libertad de cambiar de religión o su creencia, así como su libertad de manifestar su religión o su creencia, individual y colectivamente, tanto en público como en privado, por la enseñanza, la práctica, el culto y la observancia". ${ }^{4}$

De acuerdo con Romero (2012), en el sistema interamericano de protección de derechos se desarrolla el contenido y alcance de estas libertades, que se pueden traducir en los siguientes derechos:

1) Profesar una religión, es decir de tener una creencia religiosa; 2) manifestar una creencia en público o en privado, en forma individual o colectiva, esto es, dar a conocer o exteriorizar la religión que se profesa; 3) practicar los preceptos de una determinada religión en público o en privado de forma individual o colectiva, en otras palabras, llevar a cabo o realizar las convicciones religiosas; 4) conservar una religión o mantener la creencia; 5) cambiar de religión, lo que significa tener la posibilidad de dejar una religión y tomar otra, y 6) difundir una religión, lo que implicaría trasmitir las creencias religiosas (p.2)

\footnotetext{
${ }^{4}$ Artículo 19 de la Constitución Política de Colombia del año 1991.

${ }^{5}$ Romero, X. (2012). La libertad religiosa en el Sistema Interamericano de Protección de los Derechos Humanos (análisis comparativo con el ordenamiento jurídico colombiano). Revista Derecho del Estado Nueva Serie, 29. Disponible en:http.//revista.uexternado.edu.co/index.php/derest/article/view/3297/3072
} 
Juan David Jurado Ocampo \& Constanza Fraume Restrepo, La libertad religiosa y de cultos en Colombia desde la ley 133 de 1994, desarrollo constitucional y jurisprudencial para la protección de las creencias desde la perspectiva de los derechos humanos.

En consecuencia, el primer inciso del artículo 12 de la CADH (Convención Americana sobre Derechos Humanos de 1969 - instrumento ratificado por Colombia mediante ley 16/1972), habla de la libertad de conciencia y religión, y trae consigo una definición similar al artículo 19 DUDH, con algunos matices en los incisos 2,3,4, que establecen que:

(...) 2. nadie puede ser objeto de medidas restrictivas que puedan menoscabar la libertad de conservar su religión o sus creencias o de cambiar de religión o de creencias.

3. La libertad de expresar la propia religión y las propias creencias está sujeta únicamente a las limitaciones prescritas por la ley y que sean necesarias para proteger la seguridad, el orden, la salud o moral públicos o los derechos o libertades de los demás.

4. Los padres, y en su caso tutores, tienen derecho a que sus hijos o pupilos reciban la educación religiosa y moral que esté de acuerdo a sus propias convicciones.

Con una redacción similar se encuentra el artículo 18 del PIDCP (Pacto Internacional de Derechos Civiles y Políticos de 1976 - ratificado por Colombia el 29 de octubre de 1969) mediante el cual el Estado se comprometió a garantizar el ejercicio y la expresión de estas mismas libertades y todas aquellas que correspondan al ejercicio de los derechos civiles y políticos enunciados en el presente pacto.

La Asamblea General de las Naciones Unidas (ONU), recientemente; por medio de la resolución 68/169 del 18 de diciembre de 2013, sobre la: "Lucha contra la intolerancia, los estereotipos negativos, la estigmatización, discriminación, la incitación a la violencia y la violencia contra las personas basada en la religión o las creencias" ${ }^{6}$, se pronunció con ocasión

\footnotetext{
${ }^{6}$ Organización de las Naciones Unidas (2013). Asamblea General. Lucha contra la intolerancia, los estereotipos negativos, la estigmatización, la discriminación, la incitación a la violencia contra las personas basadas en la religión o las creencias. Resolución 68/169 del 18 de diciembre de 2013.
} 
Juan David Jurado Ocampo \& Constanza Fraume Restrepo, La libertad religiosa y de cultos en Colombia desde la ley 133 de 1994, desarrollo constitucional y jurisprudencial para la protección de las creencias desde la perspectiva de los derechos humanos.

de los incidentes de violencia e intolerancia que se vienen presentando alrededor del mundo en contra de las personas o minorías en razón a su religión y creencias. Se deplora en esta resolución de forma vehemente cualquier tipo de apología a la discriminación religiosa, que también pretenda atentar contras las minorías o colectividades religiosas, y al mismo tiempo promueve el respeto por la diversidad religiosa y cultural.

Esta resolución es importante, toda vez que desde el seno de la ONU se exhorta a los estados miembros adoptar medidas efectivas para que los funcionarios públicos, no discriminen a las personas por motivos de religión y por el contrario fomenten la diversidad y el pluralismo religioso, desarrollando mecanismos que permitan a las diferentes comunidades religiosas manifestar sus creencias y contribuir a la sociedad en condiciones de igualdad la cual se define: "como la conformidad de una cosa con otra, en naturaleza, forma, calidad y cantidad" , la equidad es la virtud que nos hace dar a cada uno lo que le corresponde.

Se puede observar; que desde la perspectiva del derecho internacional se promueve el ejercicio de un conjunto de libertades y derechos en el ámbito religioso, cuyos titulares son naturalmente las personas, quienes individual y colectivamente los pueden ejercer con las restricciones propias de la ley, y a su vez el Estado ostenta la obligación de respeto, garantía y protección del ejercicio pleno de estos derechos, en todas sus manifestaciones.

Por otro lado, se debe considerar que en virtud de la teoría del bloque de constitucionalidad se habla de deberes vinculantes para el Estado; a la par que la naturaleza jurídica y alcance que se pueden evidenciar en las sentencias C-225/1995, C-423/1995, C578/1995, C-191/1998, C-708/1999, C 1635/2000 de la Corte Constitucional. 
Juan David Jurado Ocampo \& Constanza Fraume Restrepo, La libertad religiosa y de cultos en Colombia desde la ley 133 de 1994, desarrollo constitucional y jurisprudencial para la protección de las creencias desde la perspectiva de los derechos humanos.

En conclusión, los tratados y convenios internacionales ratificados por Colombia que contienen desarrollo en torno a la libertad y ejercicio de las creencias religiosas son vinculantes en el derecho interno.

\section{ANÁLISIS CRÍTICO DEL RÉGIMEN JURÍDICO VIGENTE SOBRE EL DERECHO A LA LIBERTAD RELIGIOSA EN COLOMBIA: DEBILIDADES Y FORTALEZAS}

En nuestro país el derecho a la libertad religiosa como derecho fundamental se consagra el artículo 19 CP: "Se garantiza la libertad de cultos. Toda persona tiene derecho a profesar libremente su religión y difundirla en forma individual y colectiva. Todas las iglesias son igualmente libres ante la ley".

Este derecho tiene concordancias con otros derechos fundamentales como el derecho a la igualdad, la libertad de conciencia, el libre desarrollo de la personalidad y la libertad de expresar o difundir el pensamiento, comprendidos en el artículo 13,16,18,20, entre otros de la Constitución Política (CP) Y ha sido implementado por la legislación nacional a través de la ley 133/1994 "por la cual se desarrolla el Derecho de Libertad Religiosa y de Cultos, reconocido en el artículo 19 de CP", que comienza por reconocer la vigencia de los tratados internacionales ratificados por Colombia.

Además, regula y reconoce la diversidad de las iglesias y confesiones religiosas, destacando la igualdad, la libertad, la autonomía, y la personería jurídica de la que estas están sujetas. Sin embargo, enfatiza no que no son objeto de esta legislación aquellas actividades 
Juan David Jurado Ocampo \& Constanza Fraume Restrepo, La libertad religiosa y de cultos en Colombia desde la ley 133 de 1994, desarrollo constitucional y jurisprudencial para la protección de las creencias desde la perspectiva de los derechos humanos.

que se relacionan con fenómenos psíquicos y parapsicológicos, el satanismo, las prácticas mágicas $u$ otras análogas a las religiones.

Posteriormente, en sus artículos 6 y 7, la ley 133/1994, incluye un catálogo de los derechos comprendidos dentro de la libertad religiosa como expresión individual y colectiva de las personas y frente a los derechos de las confesiones religiosas como entidades constituidas, destacando en estas últimas, dos rasgos: su autonomía jurídica y su inmunidad de coacción.

En estos términos; el artículo 7 destaca que las iglesias y confesiones religiosas, tienen, entre otros, el derecho a: establecer lugares de culto o de reunión con fines religiosos; ejercer libremente el propio ministerio; conferir órdenes religiosas, designar para los cargos pastorales; comunicarse y mantener relaciones; sea en el territorio nacional o en el extranjero, con sus fieles, con otras iglesias o confesiones religiosas y con sus propias organizaciones; establecer su propia jerarquía, designar a sus correspondientes ministros libremente elegidos; tener y dirigir autónomamente sus propios institutos de formación y de estudios teológicos, en los cuales puedan ser recibidos libremente los candidatos al ministerio religioso que la autoridad eclesiástica juzgue idóneos; escribir, publicar, recibir y usar libremente sus libros y otras publicaciones sobre cuestiones religiosas; entre otros.

Así, la Corte Constitucional mediante sentencia de tutela T 200/1995 se pronunció sobre el alcance y naturaleza jurídica de las confesiones religiosas, y preciso que:

(...) cada iglesia es libre de establecer, según sus criterios y reglamentos y disposiciones con arreglo a los cuales habrán de cumplirse los objetivos inherentes a la práctica de la fe que practica. 
Juan David Jurado Ocampo \& Constanza Fraume Restrepo, La libertad religiosa y de cultos en Colombia desde la ley 133 de 1994, desarrollo constitucional y jurisprudencial para la protección de las creencias desde la perspectiva de los derechos humanos.

Las decisiones de tales autoridades, dentro de las propias competencias que la propia confesión religiosa establece, son obligatorias para los feligreses en la medida en que sus ordenamientos internos los dispongan.

De la misma manera, las religiones gozan de la libertad para establecer requisitos y exigencias en el campo relativo al conocimiento de dignidades y jerarquías así en lo referente a los sacramentos, ritos y ceremonias. Todo esto implica un orden eclesiástico que cada comunidad religiosa establece de modo independiente, sin que las autoridades del Estado puedan intervenir en su configuración ni en su aplicación, así como las jerarquías eclesiásticas tampoco están llamadas a resolver asuntos reservados de competencias estatales.

En efecto, estos son algunos de los primeros contornos de los derechos de confesiones religiosas, pues es claro que su autonomía e independencia no pueden exceder los límites permitidos por el Estado, y viceversa.

Asimismo, el Estado tiene otras prohibiciones especiales, que se ligan a su carácter laico y neutral, como el hecho de promover una iglesia o religión oficial; identificarse a través de alguna de ellas; realizar actos oficiales o simbólicos de adhesión; tomar decisiones políticas tendientes a favorecer o perjudicar una confesión religiosa, entre otras según sentencia C-817/2011 de la Corte Constitucional.

No obstante, las prohibiciones, la propia Corte mediante sentencias C-088/1994 y T493/2010 ya había precisado que el Estado también puede fijar límites y restricciones a las confesiones religiosas, siempre y cuando se adecúen a los siguientes criterios:

(...) (i) La presunción debe estar siempre a favor de la libertad en grado máximo, (ii) esta solo puede restringirse en cuanto a que la medida sea racional y 
Juan David Jurado Ocampo \& Constanza Fraume Restrepo, La libertad religiosa y de cultos en Colombia desde la ley 133 de 1994, desarrollo constitucional y jurisprudencial para la protección de las creencias desde la perspectiva de los derechos humanos.

objetivamente constituya una medida necesaria y (iii) las posibles limitaciones no pueden ser arbitrarias o discrecionales (Corte Constitucional, C-088/1994)

Debe señalarse; la ley 133/1994 no es ajena al debate; y del mismo modo no han sido pocos los cuestionamientos que se plantean con relación al creciente número de iglesias y la limitada capacidad de financiamiento de las mismas. Tan solo hasta el año 2015, se registraron más 5300 nuevas iglesias de acuerdo con el dato del Ministerio del Interior, con una dinámica de entre quince (15) y veinte registros diarios (Aguirre, 2013) ${ }^{7}$, una situación dramática, si se tiene en cuenta que en Colombia estas iglesias congregan a más de ocho (8) millones de creyentes y mueven montos cercanos a un billón de pesos al año (Jiménez $2014)^{8}$

En efecto, las iglesias registradas con personería jurídica en Colombia, según el literal c) del artículo 14 de la ley 133/1994, tienen derecho a solicitar y recibir donaciones económicas y a organizar colectas con sus fieles, para el desarrollo de sus fines misionales. Una libertad que no hace reparo alguno frente a los montos máximos que reciben estas iglesias.

Mientras, Prieto (2012) sostiene que la ley 133/1994 mezcla los derechos de la libertad religiosa como expresión colectiva, con los derechos de las personas jurídicas especiales, y a su vez advierte algunos indicios de trato desigual entre las confesiones religiosas al permitir la existencia de tres (3) tipos de personería jurídica.

\footnotetext{
${ }^{7}$ Aguirre, A. (6 de octubre de 2013). Entre 15 y 20 nuevas iglesias registradas en Colombia. El Tiempo. Disponible en: http:// www.eltiempo.com/archivo/documentos/CMS-13103493

8 Jiménez J. (25 de enero de 2014). Escándalos que han salpicado a las iglesias evangélicas de Colombia. El Espectador. Disponible en: http:// www.elespectador.com/noticias/judicial/escandalos'han`salpicado-iglesias evangelicas de`colomb`articulo-470881.
} 
Juan David Jurado Ocampo \& Constanza Fraume Restrepo, La libertad religiosa y de cultos en Colombia desde la ley 133 de 1994, desarrollo constitucional y jurisprudencial para la protección de las creencias desde la perspectiva de los derechos humanos.

(...) personería jurídica de derecho público eclesiástico (para la iglesia católica y para las personas jurídicas canónicas: cfr. art. IV del Concordato); personería jurídica especial (para las demás iglesias y confesiones); y personería jurídica del derecho privado (que se puede adquirir o conservar) 9 .

Sin embargo, la Corte Constitucional en su sentencia C-350/1994, precisó que, con sujeción a la igualdad religiosa, determinada religión por más extendida que sea, no puede recibir un tratamiento privilegiado por parte del Estado, pues de acuerdo con la Carta Política, todas las confesiones religiosas en Colombia ostentan igual valor jurídico ante la ley.

Hace poco el Gobierno colombiano, a través de su Plan Nacional de Desarrollo para el período cuatrienal (2014-2018), se comprometió a través de la ley 1753 de 2015 a promover la libertad religiosa, de cultos y de conciencia, sobre la base de criterios de equidad y armonía institucional, especificando que:

(...) emprenderá acciones que promuevan el reconocimiento de las formas asociativas de la sociedad basadas en los principios de libertad religiosa, de cultos y conciencia.

El Gobierno Nacional formulará y actualizará la política pública en materia de la participación de entidades religiosas, garantizando la libertad e igualdad religiosa en términos de equidad y reconociendo su aporte al bien común local, regional y nacional (art. 244) ${ }^{10}$.

\footnotetext{
${ }^{9}$ Prieto V (2012). Reconocimiento jurídico de las entidades religiosas en el derecho colombiano: análisis crítico de la ley estatutaria de la libertad religiosa. Bogotá: Universidad de la Sabana.

${ }^{10}$ Congreso de la República de Colombia. (2015) Ley 133. Por la cual se expide el Plan Nacional de Desarrollo 2014-2018 "Todos por un nuevo país".
} 
Juan David Jurado Ocampo \& Constanza Fraume Restrepo, La libertad religiosa y de cultos en Colombia desde la ley 133 de 1994, desarrollo constitucional y jurisprudencial para la protección de las creencias desde la perspectiva de los derechos humanos.

Una visión programática que coyunturalmente puede ser excluida en el contexto político del postconflicto en Colombia, pues en los términos del Acuerdo Final para la Terminación del Conflicto y la Construcción una Paz Estable y Duradera, suscrito

El 24 de agosto de 2016 entre el Gobierno colombiano y las FARC-EP, sólo consideró la participación de las comunidades religiosas en los procesos de seguimiento y control de consumo de drogas. Nada más. En tal sentido, dentro del punto cuatro del Acuerdo de La Habana sobre la solución de drogas ilícitas, se estableció que:

Para garantizar la revisión y el ajuste participativo de la política frente al consumo con base en los principios antes descritos, el Gobierno creará una instancia nacional con representantes de las autoridades con la competencia en el tema, instituciones científicas, centros especializados, instituciones educativas, asociaciones de padres y madres de familia, comunidades religiosas y personas consumidoras (núm. 4.2.1.3, énfasis fuera de texto).

\section{EL DERECHO A LA LIBERTAD RELIGIOSA COMO EXPRESIÓN COLECTIVA}

Para Escudero (2011) la libertad religiosa es una libertad pública en todo el sentido de la palabra, cuyo mayor avance se resume (frente a la Constitución anterior) en el reconocimiento pleno del Estado de las libertades del individuo para la escogencia de su religión.

${ }^{11}$ Congreso de la República de Colombia. (2015) Ley 133. Por la cual se expide el Plan Nacional de Desarrollo 2014-2018 "Todos por un nuevo país". 
Juan David Jurado Ocampo \& Constanza Fraume Restrepo, La libertad religiosa y de cultos en Colombia desde la ley 133 de 1994, desarrollo constitucional y jurisprudencial para la protección de las creencias desde la perspectiva de los derechos humanos.

El doctrinante español Betrián (2012), ${ }^{12}$ sugiere (desde la perspectiva del derecho español) que para hablar de libertad religiosa en una sociedad democrática, se deben considerar al menos tres elementos claves para integrarse al modelo de derechos humanos vigente: el pluralismo, la tolerancia y la apertura.

El artículo primero de la Constitución Política señala que Colombia es un Estado social de derecho: "organizado en forma de República unitaria, descentralizada, con autonomía de sus entidades territoriales, democrática, participativa y pluralista, fundada en el respeto de la dignidad humana (...)". Entre tanto la Corte Constitucional mediante sentencia T-403/1992 planteó que:

(...) Las libertades de culto y expresión ostentan el carácter de derechos fundamentales, no solamente por su consagración positiva y su naturaleza de derechos de aplicación inmediata, sino, sobre todo, por su autorrealización del individuo en su vida en comunidad.

Es una sociedad cuyo orden jurídico garantiza las concepciones religiosas o ideológicas de sus miembros, el Estado debe ser especialmente cuidadoso en sus intervenciones, pues ellas pueden inferir la independencia y libertad de las personas que profesan una confesión o un credo.

De ahí que; a partir de la Constitución Política de 1991, Colombia “hizo tránsito de un estado confesional a un Estado Laico y pluralista en materia de confesiones religiosas". De ahí que se pueda hablar de la secularización del Estado colombiano. Posteriormente, el pluralismo religioso fue retomado por la Corte mediante sentencia 350/1994, así:

\footnotetext{
12 Betrián, P (2012) Cuestiones actuales sobre el derecho de la libertad religiosa. En: E.H Fuentes \& B, Abreu (Coord.) Perspectivas Iberoamericanas de asuntos constitucionales (pp 309-331) Bogotá. Unidad Jorge Tadeo Lozano.
} 
Juan David Jurado Ocampo \& Constanza Fraume Restrepo, La libertad religiosa y de cultos en Colombia desde la ley 133 de 1994, desarrollo constitucional y jurisprudencial para la protección de las creencias desde la perspectiva de los derechos humanos.

Mientras que la constitución de 1886 garantizaba la libertad de cultos, pero subordinándola a la conformidad del culto respectivo con la moral cristiana, y en todo caso, sometiendo su ejercicio a las leyes, el Constituyente de 1991, por el contrario, optó por liberalizar la libertad de culto, sin consagrar límites constitucionales expresos a su ejercicio. Esto significa que, conforme a la Constitución de 1991, puede haber cultos religiosos que no sean conformes a la moral cristiana y no por ello sean inconstitucionales, mientras que tales cultos no eran admisibles en el anterior ordenamiento jurídico.

Igualmente, la sentencia T-388/2009 de la Corte Constitucional aclaró que:

Uno de los rasgos distintivos del Estado es, por tanto, su apertura al pluralismo. Tal apertura se conecta al menos con tres dimensiones: ser el reflejo de una sociedad que (i) admite y promueve de manera expresa el hecho de la diversidad (artículo $7^{\circ}$ Superior): (ii) aprecia de modo positivo las distintas aspiraciones y valoraciones hasta el punto de proteger de modo especial la libertad religiosa, de conciencia y pensamiento así como la libertad de expresión y (iii) establece los cauces jurídicos, políticos y sociales que servirán para dirimir los posibles conflictos que se presenten en virtud de las diferencias vigentes en un momento determinado.

Sin duda en esta parte se puede encuadra el planteamiento de Jorge Munévar (2005), cuando dice que: "la libertad religiosa establece la relación entre el poder del Estado y los ciudadanos y entre el Estado y las organizaciones religiosas" (p.247) ${ }^{13}$.

En retrospectiva, el pluralismo es evidentemente una de las mayores conquistas del Estado social de derecho, en lo que a la diversidad religiosa se refiere, particularmente si se

${ }^{13}$ Munévar, J. (2005) La libertad religiosa Colombia orígenes y consecuencias, En: B. Greising \& D. Varga. Globalización y diversidad religiosa en Colombia (pp.247-258). Bogotá Universidad Nacional. 
Juan David Jurado Ocampo \& Constanza Fraume Restrepo, La libertad religiosa y de cultos en Colombia desde la ley 133 de 1994, desarrollo constitucional y jurisprudencial para la protección de las creencias desde la perspectiva de los derechos humanos.

observa el contenido de la constitución de 1886, el fuerte pulso conflictivo que existió entre el Estado y la Iglesia católica durante la segunda mitad del siglo XIX, y los concordatos sucesivos que suscribieron hasta 1973 (Prieto, 2001) ${ }^{14}$.

En la actualidad existen contextos donde el ejercicio de la libertad religiosa se puede ver restringido, naturalmente, debido entre otras cosas a la dificultad de garantizarlo con las mismas libertades que el resto de los ciudadanos, tal como es el caso de los centros penitenciarios, dentro de los centros penitenciarios, dentro de los cuales se hacen restrictivos otros derechos fundamentales, algo frente a lo cual la Corte constitucional mediante sentencia T-077 de 2015, se ha pronunciado en los siguientes términos:

"la libertad de cultos es uno de los derechos a ser garantizado a la población reclusa, pero su goce se debe dar dentro del marco de seguridad y orden de los establecimientos penitenciarios. Puesto que esta garantía defiende que las personas lleven un modo de vida que sea expresión cabal de sus convicciones religiosas más arraigadas, cualquier restricción debe estar precedida de un análisis de razonabilidad y proporcionalidad. De lo contrario, se le impondrá al creyente una carga desproporcionada de incumplir con los dogmas de su religión, sin que ello fuera necesario para la protección de un interés público. En este punto se debe recordar que el amparo de la libertad religiosa resulta inane si el Estado se niega a resguardar las manifestaciones más valiosas de la experiencia religiosa, que constituyen frente de complacencia para cada persona. Como lo ha reconocido este Tribunal, la imposibilidad de coherencia entre lo que profesa y práctica el individuo puede generar un inmenso grado de sufrimiento, por lo que a las autoridades penitenciarias les corresponden garantizar en la mayor medida posible que los internos sean fieles a su credo (Corte Constitucional, T 077, 2015)".

\footnotetext{
${ }^{14}$ Prieto V (2001). Congreso latinoamericano sobre la libertad religiosa. Lima Fondo Editorial de la Pontifica Universidad Católica de Perú.
} 
Juan David Jurado Ocampo \& Constanza Fraume Restrepo, La libertad religiosa y de cultos en Colombia desde la ley 133 de 1994, desarrollo constitucional y jurisprudencial para la protección de las creencias desde la perspectiva de los derechos humanos.

Para concluir, es claro que la libertad religiosa, como derecho fundamental, no es necesariamente, ni tiene atribuciones de ser un derecho absoluto; y en particular como lo menciona la Corte; cuando se trata de desconocer o restringir el ejercicio de otros derechos fundamentales, como puede ser el caso de la vinculación personal al servicio de la iglesia sin el respeto de las garantías mínimas del derecho al trabajo; la discriminación de las personas en situación de discapacidad al interior de algunas iglesias, amparadas en la autonomía e independencia jurídica que ostentan; o la práctica de rituales que pueden conllevar de alguna manera atentar en contra de la dignidad humana de los fieles o terceros, entre otros.

\section{AVANCES Y LIMITACIONES A LA LIBERTAD RELIGIOSA EN COLOMBIA, EL DESARROLLO DE UN MODELO DE ESTADO LAICO Y NEUTRAL}

Con la el cumplimiento de los 25 años de la CP de Colombia, y considerando la resolución 168/169 del 18 de diciembre de 2013 de la Asamblea General de la ONU sobre la lucha de la libertad religiosa en el mundo, el Gobierno Colombiano recientemente expidió el decreto 1079/2016, a través del cual se declaró el 4 de julio (de cada año) como el día Nacional de la Libertad Religiosa y de Cultos. En efecto, este decreto establece que:

(...) el Gobierno Nacional, a través del Ministerio del Interior, y en articulación con las entidades territoriales, coordinará con las Iglesias, Confesiones, Denominaciones, Comunidades Religiosas; Federaciones, Confederaciones, Asociaciones de Ministros y distintas Organizaciones sociales religiosas, jornadas de reflexión institucional, de oración, actos religiosos conmemorativos de difusión y 
Juan David Jurado Ocampo \& Constanza Fraume Restrepo, La libertad religiosa y de cultos en Colombia desde la ley 133 de 1994, desarrollo constitucional y jurisprudencial para la protección de las creencias desde la perspectiva de los derechos humanos.

socialización sobre el respeto e igualdad de las religiones y cultos; permitiendo en estos espacios de diálogo y debate, en todos los ámbitos de la vida social, cultural y política, el efectivo disfrute de las garantías del ejercicio de la libertad religiosa ${ }^{15}$.

Una medida incluyente que sumada al objetivo del artículo 244 del Plan Nacional de Desarrollo de la ley 1753/2015, sin duda favorece el desarrollo del ambiente participativo, democrático y pluralista, en pro de las comunidades religiosas, que luchan incansablemente por reconocimiento institucional en condiciones de legitimidad e igualdad, y en medio de una sociedad altamente conservadora, afectada por la violencia e inclinada por las costumbres tradicionalistas.

Hoy, muchas comunidades religiosas sin ánimo de lucro gozan de privilegios tributarios y económicos importantes, y no así continúan enfrascadas en pleitos judiciales por tratar de alcanzar los mismos privilegios y reconocimientos que la Iglesia católica o instituciones congregadas en la ley canónica en Colombia.

En esta perspectiva; es importante recordar que la Corte Constitucional mediante sentencia T-621/2014 resolvió favorablemente, en sede de revisión, una acción de tutela instaurada en contra de la Corporación Autónoma Regional para la defensa de la Meseta de Bucaramanga para lograr la exoneración del pago del impuesto de la sobretasa ambiental correspondiente al año 2012 y la devolución del dinero pagado. En esta decisión, la Corte amparó el derecho fundamental del artículo 13 de la Constitución Política y le ordenó a la mencionada corporación, que:

(...) en aras de salvaguardar el principio de igualdad, exima a la Iglesia Cristiana Ministerios El Dios Altísimo del pago del impuesto a la sobretasa ambiental, hasta

\footnotetext{
${ }^{15}$ Ministerio del Interior. (2016) Decreto 1079. Por el cual se declara el Día Nacional de la Libertad Religiosa y de Cultos.
} 
Juan David Jurado Ocampo \& Constanza Fraume Restrepo, La libertad religiosa y de cultos en Colombia desde la ley 133 de 1994, desarrollo constitucional y jurisprudencial para la protección de las creencias desde la perspectiva de los derechos humanos.

cuando se expida una ley que desarrolle la igualdad de las iglesias legalmente constituidas con relación a este gravamen.

La Corte, se permitió el derecho de exigirle al Gobierno nacional que promoviera una iniciativa legislativa para regular con eficacia e igualdad las condiciones tributarias de las comunidades religiosas en Colombia.

Un caso similar se resolvió en sentencia T-073/2016, particularmente contra la corporación de Bucaramanga, y una vez más la Corte falló favorablemente a las pretensiones de la Iglesia demandante, concedió la exención tributaria del mismo impuesto nuevamente.

Prieto $(2012)^{16}$, ya había advertido que: "la Ley Estatutaria es imprecisa cuando establece (art 7, parágrafo) que los Concejos Municipales podrían conceder a las instituciones religiosas exenciones de los impuestos y contribuciones de carácter local en condiciones de igualdad para todas las confesiones e iglesias".

Según el autor se presentaba un problema de interpretación por cuanto no se entendía sí el término "instituciones religiosas" era lo mismo que "confesiones religiosas" o si solamente aplicaba estas exenciones tributarias en favor de las iglesias que tenían un reconocimiento jurídico especial o de derecho público eclesiástico.

Entre tanto, la Corte Constitucional resolvió mediante sentencia C.224/2016, una demanda de inconstitucionalidad presentada en contra del artículo 8 de la ley 1643/2013, "por la cual se declara patrimonio cultural inmaterial de la Nación la Semana Santa de Pamplona; departamento de Norte Santander, y se dictan otras disposiciones".

\footnotetext{
${ }^{16}$ Prieto V (2012). Reconocimiento jurídico de las entidades religiosas en el derecho colombiano: análisis crítico de la ley estatutaria de la libertad religiosa. Bogotá: Universidad de la Sabana.
} 
Juan David Jurado Ocampo \& Constanza Fraume Restrepo, La libertad religiosa y de cultos en Colombia desde la ley 133 de 1994, desarrollo constitucional y jurisprudencial para la protección de las creencias desde la perspectiva de los derechos humanos.

El argumento de esta demanda fue que esta norma atenta contra el carácter laico propio de un Estado social de derecho, pues concede un privilegio a la comunidad religiosa católica, en perjuicio de la libertad religiosa y de cultos consagrada en el artículo 19 de la CP. Pese a esto, la Corte afirmó:

(...) la neutralidad que impone la laicidad frente a los cultos religiosos no prohíbe ciertos lugares (por ejemplo, de culto), ciertas obras artísticas (pinturas y esculturas) y arquitectónicas (templos, monasterios), o incluso ciertas manifestaciones religiosas sean protegidas por el Estado en razón de su proyección como patrimonio cultural.

Sin embargo, al estar en tensión el principio de constitucional de laicidad y neutralidad religiosa con el deber - también constitucional-de protección de patrimonio cultural, es preciso ponderar varios aspectos.

Los aspectos a los que alude la Corte son tres: Que existan elementos de juicios objetivos y razonables que permitan determinar que esos bienes culturales son o no pertenecen al patrimonio cultural de la nación, más allá de meras coincidencias o referencias con ciertos sectores; la noción de patrimonio cultural no está asociada a un criterio de mayorías, pues no tendría cabida el respeto por las minorías en nuestro Estado; y El Estado no puede perder su neutralidad, mediante decisiones que favorezcan de manera particular a una sola comunidad.

Finalmente, la Corte declaró inexequible esta norma que consideró entre otras cosas que:

(...) es evidente que con el artículo demandado se establece una forma de relación de inconstitucionalidad Estado- Iglesia Católica, en una faceta de inversión de recursos del ente municipal de Pamplona, por dos razones principales.

En primer lugar, el significado mismo del término sugiere una idea religiosa. Tan es así que la Real Academia de la Legua Española le otorga el siguiente significado: 
Juan David Jurado Ocampo \& Constanza Fraume Restrepo, La libertad religiosa y de cultos en Colombia desde la ley 133 de 1994, desarrollo constitucional y jurisprudencial para la protección de las creencias desde la perspectiva de los derechos humanos.

"acto de ir ordenadamente de un lugar a otras muchas personas con algún fin público y solemne, frecuentemente religioso"; agregándole el término de condición Semana Santa, no cabe duda de su relación directa con un acto solemne importante para la religión católica. En cuanto a las imágenes que en ella se exponen, cobra mucha más vigencia su relación con el acto religioso, pues en ellas se representa el Ministerio de la Pasión, Muerte y Resurrección de Jesucristo.

En segundo lugar, la relación Estado- Iglesia se expone con más fuerza, cuando el legislador decide involucrar a la Arquidiócesis de Pamplona, entendida como "una jurisdicción eclesiástica de la Iglesia Católica en Colombia", otorgándole los calificativos de creadora, gestora, promotora de dichas procesiones (Corte Constitucional, c-224/2016)

Al igual que en estos momentos la Corte Constitucional está resolviendo una demanda similar de inexequibilidad en contra de la ley 891/2004

Por lo cual se declara Patrimonio Cultural Nacional las Procesiones de Semana Santa y el Festival de Música Religiosa de Popayán, en el departamento del Cauca, se declara monumento Nacional un inmueble urbano, se hace un reconocimiento y se dictan otras disposiciones.

Si de seguir la misma línea argumentativa de la sentencia anterior, posiblemente se lleve a declarar la inexequibilidad de esta ley, sobre la base de los principios de neutralidad y laicidad del Estado social de derecho, pues al igual que las procesiones de Pamplona (Santander), las de Popayán se desarrollan solemnes y multitudinarias celebraciones religiosas de carácter eminentemente católica.

En cuanto a las limitaciones del ejercicio de la libertad de culto y religión; el Consejo de Estado mediante sentencia 01392/2014, al decidir desfavorablemente una impugnación de una acción de tutela, que estaba dirigida en contra, considero lo siguiente: 
Juan David Jurado Ocampo \& Constanza Fraume Restrepo, La libertad religiosa y de cultos en Colombia desde la ley 133 de 1994, desarrollo constitucional y jurisprudencial para la protección de las creencias desde la perspectiva de los derechos humanos.

En tal virtud, el contenido y los alcances de la libertad religiosa, como todo derecho fundamental, también se encuentra sujeto a ciertos límites, que no son otros que los derechos de los otros, lo que permita el legítimo ejercicio del derecho propio, de los ajenos y de las exigencias como el orden público, la salubridad y seguridad públicas, la moralidad y la tranquilidad que hagan posible la convivencia pacífica en la sociedad

En este caso el accionante pretendía censurar la presentación de una artista en el Museo Santa Clara en Bogotá propiciada por el Ministerio de Cultura, para considerar que esta exposición atentaba contra la dignidad y la libertad religiosa y de cultos:

Ello es así, en razón que la expresión artística no está afectando ninguno de los componentes del derecho, toda vez que la obra se está exhibiendo en un espacio diseñado para mostrar las expresiones artísticas colombianas, no están infiriendo en culto, o religión profesado por el accionante, ni le está implicando o limitando la práctica de sus creencias.

Por el contrario, acceder a lo solicitado por ellos, como restringir la exposición, si vulneraría el derecho a la libertad de expresión de la autora de la obra (Consejo de Estado 01392/2014)

Sin embargo, se puede considerar importante protección que se ha concedido a través del Código Penal colombiano; mediante ley 1482/2011, frente a la comisión de conductas punibles discriminatorias que atenten contra las personas, por el hecho de pertenecer a determinada religión. El artículo 134B del Código Penal declara que será delito:

El que promueva o instigue actos, conductas, comportamientos constitutivos de hostigamiento, orientado a causarle daño físico o moral a una persona, comunidad o pueblo, por razón de su raza, etnia, religión, nacionalidad, ideología política o filosófica, sexo u orientación sexual, incurrirá en prisión de doce (12) a treinta y seis (36) meses y multa de 
Juan David Jurado Ocampo \& Constanza Fraume Restrepo, La libertad religiosa y de cultos en Colombia desde la ley 133 de 1994, desarrollo constitucional y jurisprudencial para la protección de las creencias desde la perspectiva de los derechos humanos.

diez (10) a quince (15) salarios mínimos legales mensuales vigentes, salvo que la conducta constituya delito sancionable con pena mayor.

\section{CONCLUSIONES}

Colombia es un Estado social democrático de Derecho, con personería jurídica internacional, y por virtud del principio ius cogens, es un sujeto de derecho y obligaciones, entre ellas la que corresponde al cumplimiento de los tratados internaciones y convenios internacionales que suscribe, en tal sentido está vinculado a ellos, y de manera casi automática se encuentran integrados, por mandato constitucional, al ordenamiento jurídico interno, según el artículo 93 de la CP y la teoría del bloque de constitucionalidad; el cual artículo señala:

Los tratados y convenios internacionales ratificados por el Congreso, que reconocen los derechos humanos y que prohíben su limitación en los estados de excepción, prevalecen en el orden interno.

Los derechos y los deberes consagrados en esta Carta, se interpretarán de conformidad con los tratados internacionales sobre derechos humanos ratificados por Colombia.

Además, la teoría del bloque de constitucionalidad permite entender que la Constitución Política no se agota en su articulado, sino que implica la integración con otras normas.

La estructura y contenido del derecho del artículo 19 de la Carta Política es muy sencilla "se garantiza la libertad de culto. Toda persona tiene derecho a profesar libremente su religión y difundirla en forma individual y colectiva"; en sentido textual contiene tres derechos: El de profesar libremente una religión; el de difundir libremente la religión, de 
Juan David Jurado Ocampo \& Constanza Fraume Restrepo, La libertad religiosa y de cultos en Colombia desde la ley 133 de 1994, desarrollo constitucional y jurisprudencial para la protección de las creencias desde la perspectiva de los derechos humanos.

forma individual y colectiva; la libertad de cultos, es decir "el derecho de toda persona a celebrar las ceremonias, ritos o actos propios de las convicciones religiosas que profesa".

Es decir; el derecho consagrado el artículo 19 de la CP de Colombia, es un derecho humano innato, intransferible e irrenunciable de las personas, a su vez está regulado por dos sistemas de protección internacional de derechos humanos, uno de carácter universal de la ONU y otro de carácter regional, integrado por el Sistema Interamericano de Derechos Humanos de la OEA.

En desarrollo del artículo 19 de la Constitución, el artículo 60 de la ley 133 de 1994, estatutaria de libertad religiosa y de cultos preciso el contenido de este derecho fundamental en las siguientes garantías: La de profesar cualquier creencia, cambiarla, abandonarla o no profesar ninguna; la de precisar actos de culto, modo público o privado, individualmente o de grupo; la de recibir digna sepultura, con observancia de los ritos y preceptos de la religión escogida; la de celebrar matrimonio de acuerdo a su religión y que este tenga efectos civiles; la de no ser obligado a practicar actos de culto contrarios a sus convicciones; la de recibir asistencia religiosa y moral según sus convicciones; la de elegir educación religiosa y moral según propias convicciones; la de no ser discriminado en el trabajo o en cargos públicos por razón de preferencias religiosas; la de reunirse y asociarse para desarrollar actividades religiosas.

No obstante, la amplia determinación de estas garantías, faltaba establecer alcance práctico de los derechos de las minorías frente a una mayor católica dominante, y el papel del Estado respecto de los derechos de esas minorías.

Esta tarea, desarrollada por la jurisprudencia, tuvo tres escenarios jurídicos: el derecho a la igualdad de trato de individuos y comunidades distintas de la católica; el principio de separación entre las iglesias y el Estado y el desarrollo de los principios del Estado 
Juan David Jurado Ocampo \& Constanza Fraume Restrepo, La libertad religiosa y de cultos en Colombia desde la ley 133 de 1994, desarrollo constitucional y jurisprudencial para la protección de las creencias desde la perspectiva de los derechos humanos.

laico fijados por la Corte Constitucional, como son los principios de neutralidad y la prohibición de la persecución por motivos religiosos, todo ello conforme a la regla según la cual "los derechos constitucionales no pueden ser disueltos en un cálculo utilitario sobre el colectivo, ni pueden ser sometidos al criterio de las mayorías, ya que esos derechos son precisamente limitaciones al principio de mayoría y las políticas destinadas a satisfacer el colectivo" como se señala en la sentencia C-309 de 1997, M.P Alejandro Martínez Caballero, consideración Jurídica 6.

También queda planteado el problema de las tensiones que surgen en escenarios como el trabajo, la educación cuando surgen colisiones entre distintos derechos y el derecho de libertad religiosa. Así, y desde la perspectiva de la igualdad de trato entre las distintas iglesias, la neutralidad del Estado en materia religiosa y la aplicación de la ponderación como instrumento para superar la colisión entre principios y derechos se reconstruyen los momentos fundamentales de la línea jurisprudencial.

Así mismo, de acuerdo con la Corte Constitucional, cada iglesia es libre de fijar, según sus criterios, los reglamentos y disposiciones internos; la coercitividad de sus decisiones, la libertad para establecer requisitos y exigencia en el campo relativo al reconocimiento de dignidades y jerarquías, entre otros.

Sin embargo, en los últimos años no ha habido un desarrollo legislativo significativo en materia de libertad religiosa en Colombia, y es claro que algunos aspectos normativos requieren de una reglamentación más clara y precisa, para evitar interpretaciones abiertas, permisivas, acomodadas; tal es el caso del requisito de arraigo de la confesión religiosa o iglesia para acceder a la posibilidad de establecer convenios de derechos público con el Estado (y todo lo que esto conlleva a institucionalizar sus propias doctrinas). 
Juan David Jurado Ocampo \& Constanza Fraume Restrepo, La libertad religiosa y de cultos en Colombia desde la ley 133 de 1994, desarrollo constitucional y jurisprudencial para la protección de las creencias desde la perspectiva de los derechos humanos.

Puesto que, para el caso de la Unión Europea y en particular el caso de España, se ha determinado que para que una comunidad religiosa pueda tener arraigo ( o arraigo notorio como allá lo llaman) con el mismo propósito, debe llevar inscrita en el registro de entidades religiosas, por lo menos treinta años, salvo que la entidad acredite un reconocimiento en el extranjero de, al menos, sesenta años de antigüedad, y lleve inscrita en el citado registro al menos de quince años, de acuerdo con el real decreto (593/2015).

Otra precisión que sería necesaria, es la que se relaciona con las extinciones tributarias, que en ciertas condiciones terminan siendo desconocidas o vulneradas en contra de las confesiones religiosas sin ánimo de lucro, que con el argumento de la autonomía fiscal de las entidades territoriales, algunos municipios sobreponen con cierta frecuencia a toda una línea de pronunciamientos jurisprudenciales de la Corte Constitucional.

Finalmente, el derecho a la libertad religiosa y de cultos, sufrió un notable cambio con la expedición de la Carta de 1991, en el intento de pasar de un Estado católico confesional a un Estado laico, que supone para el Estado el deber ser neutral en materia religiosa y la garantía de la libertad religiosa y de cultos, dentro de una formulación que incluye el derecho a las opciones agnósticas o ateas.

En síntesis, es importante tener en cuenta que el derecho a la libertad religiosa, no es un derecho absoluto y el Estado tiene prohibiciones especiales, que van ligadas a su carácter laico neutral, como el hecho de promover una iglesia o religión oficial; identificarse con alguna de ellas; realizar actos oficiales o simbólicos de adhesión; tomar decisiones políticas tendientes a favorecer o perjudicar una confesión religiosa, entre otras, y tal como se plantea en la sentencia C-817/2011 de la Corte Constitucional. 